\section{Incarcerated Bile Duct Adenoma as a Rare Cause of Acute Cholestatic Pancreatitis}

A 64-year old female patient was admitted because of severe epigastric abdominal pain and reduced general condition. Seventeen years ago she underwent a cholecystectomy. Severe acute biliary panereatitis was suspected, and an endoscopic retrograde cholangiopancreaticography (ERCP) was performed. On endoscopy, an incarcerated tumor of the papilla of Vater was found as the cause of pancreatitis, leading to a $1.5 \mathrm{~cm}$ stenosis of the distal common bile duct on ERC. After performing a large endoscopic sphincterotomy (EST), portions of a livid-reddish tumor prolapsed into the duodenum (Figure 1), Laboratory results showed leucocytosis, an elevated bilirubin level of $109 \mu \mathrm{mol} / \mathrm{I}$, hyperamylasemia and hyperlipasemia of $6,800 \mathrm{U} / 1$ and $22,000 \mathrm{U} / 1$, respectively. Bioptic histologic test results confirmed an adenoma (Figure 2). Partial incarceration of the bile duct adenoma in the ampullary region caused obstruction leading to jaundice. A surgical revision of the remaining portion of the adenoma was delayed because of coronary heart disease necessitating bypass surgery three months later. Due to the high risk of major abdominal surgery, the patient refused surgical removal of the adenoma. She is well now, six months after the acute pancreatitis. Acute pancreatitis requires cooperation between the gastroenterologist and the surgeon. In severe cases when a biliary genesis is suspected, emergency ERCP with EST is a generally accepted therapy (1). The results of animal experiments suggest that the severity of pancreatitis correlates with bile duct occlusion (2). In the case presented here, the extremely rare diagnosis of an incarcerated bile duct tumor could be established, and EST led to a relief of the patient's bile duct ocelusion and pancreatitis. Benign biliary tract tumors like adenomas or papillomas account for only $1 \%$ of all biliary tract neoplasms (3). In case of biliary malignancy, bile duct occlusion combined with hyperamylasemia oceurs significantly more often (4). Bile tract adenomas are considered as precancerous conditions (5); in this case the greatly increased risk of abdominal surgery precluded operative removal of the tumor.

\section{T. Körner ${ }^{1}$, H. Kronsbein ${ }^{2}$, C. H. Hammar ${ }^{3}$}

'Department of Internal Medicine II. Academic Hospital of Suhl

Pathological Institute. Academic Hospital of Fulda and Department of Internal Medicine II. Academic Hospital of Fulda

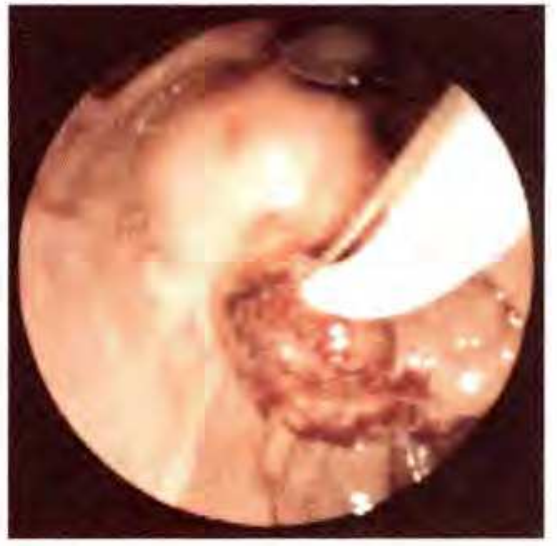

Figure 1: Endoscopic view of the incarcerated papillary tumor

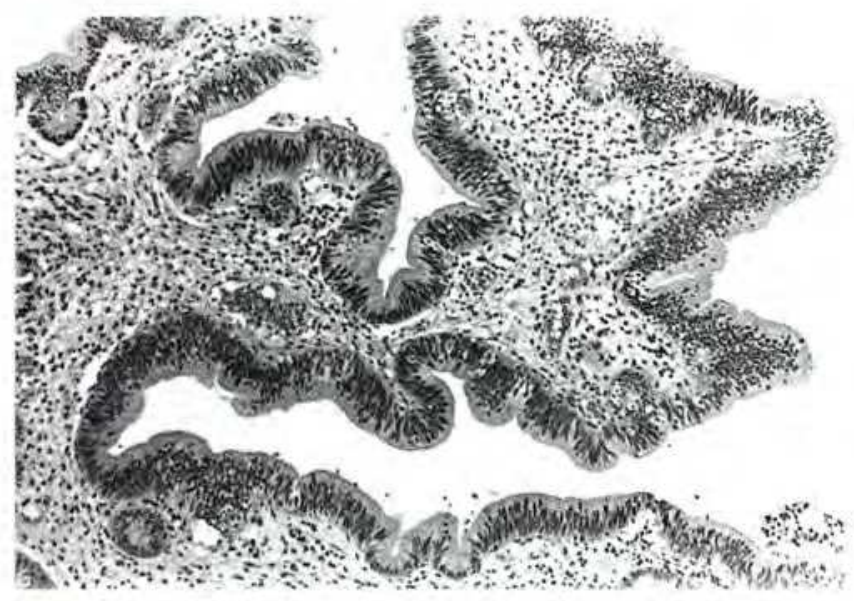

Figure 2: Histological appearance of the tumor biopsy showing adenoma.

\section{References}

1. Neoptolemos, JP, Stonelake P, Radley S: Endoscopic sphincterotomy for acute pancreatitis, Hepato-Gastroenterology 1993:40: $550-555$

2. Rünzi M. Saluja A. Lerch MM. et al.: Early ductal decompression prevents the progression of biliary pancreatitis: an experimental study in the opossum. Gastroenterology 1993; 105: $157-164$.

3. Hagenmüller F: Tumore des biliären Systems. In: Ottenjan R. Classen M (eds.): Gastroenterologische Endoskopie. Enke, Stuttgart 1991: 234-251.

4. Sivak MV: Gastroenterologic Endoscopy. W. B. Saunders, Philadelphia 1987.

5. Albores-Saavedra J, Henson DE: Benign tumors of the gallbladder. In: Tumors of the gallbladder and extrahepatic bile ducts. Armed Forces Institute of Pathology, Washington 1984: $17-24$.

Corresponding Author

T. Körner. M.D.

Department of Internal Medicine 2

Academic Hospital of Suhl

Albert-Schweitzer-Straße 2

98503 Suhl

Germany 